\title{
Prevalence and outcomes of pulmonary hypertension after percutaneous closure of atrial septal defect: a systematic review and meta-analysis
}

\author{
Selai Akseer (10 ${ }^{1,2}$, Eric Horlick ${ }^{3}$, Varnita Vishwanath ${ }^{3}$, Benjamin Hobbes ${ }^{3}$, \\ Ella Huszti ${ }^{2,4}$, Susanna Mak ${ }^{5}$, Douglas S. Lee ${ }^{1,2,6}$ and Lusine Abrahamyan ${ }^{1,2}$
}

Affiliations: ${ }^{1}$ Toronto General Hospital Research Institute, University Health Network, Toronto, ON, Canada. ${ }^{2}$ Institute of Health Policy, Management and Evaluation (IHPME), University of Toronto, Toronto, ON, Canada. ${ }^{3}$ Toronto Congenital Cardiac Centre for Adults, Peter Munk Cardiac Centre (PMCC). University Health Network, Toronto, ON, Canada. ${ }^{4}$ Biostatistics Research Unit, University Health Network, Toronto, ON, Canada. ${ }^{5}$ Division of Cardiology, Mount Sinai Hospital, Toronto, ON, Canada. ${ }^{6}$ ICES, Toronto, ON, Canada.

Correspondence: Lusine Abrahamyan, Toronto General Hospital Research Institute, 10th Floor Eaton North, Room 237, 200 Elizabeth Street, Toronto, ON M5G 2C4, Canada. E-mail: lusine.abrahamyandutoronto.ca

@ERSpublications

We aimed to assess PH in patients with ASD and the effect of percutaneous ASD closure. We found that closure of ASDs can reduce mean systolic pulmonary arterial pressure and $\mathrm{PH}$ prevalence. The clinical definition of $\mathrm{PH}$ based on cut-off values varied. https://bit.ly/3gjD22o

Cite this article as: Akseer S, Horlick E, Vishwanath V, et al. Prevalence and outcomes of pulmonary hypertension after percutaneous closure of atrial septal defect: a systematic review and meta-analysis. Eur Respir Rev 2020; 29: 200099 [https://doi.org/10.1183/16000617.0099-2020].

\section{ABSTRACT}

Background: Atrial septal defect (ASD) is a common form of congenital heart disease. Significant shunts may increase the risk of developing pulmonary hypertension (PH). We aimed to describe current $\mathrm{PH}$ definitions, evaluate $\mathrm{PH}$ prevalence and the effect of $\mathrm{PH}$ on outcomes in patients undergoing percutaneous ASD closure.

Methods: EMBASE, MEDLINE and Cochrane databases were systematically searched. Studies reporting $\mathrm{PH}$ prevalence or mean systolic pulmonary arterial pressure (sPAP) before and after percutaneous ASD closure in adults were included. We conducted meta-analyses to obtain summary estimates for $\mathrm{PH}$ prevalence and mean sPAP.

Results: 15 articles with a total of 1073 patients met the eligibility criteria. Studies applied variable $\mathrm{PH}$ definitions. $\mathrm{PH}$ prevalence and mean sPAP levels decreased in all studies after closure. The pooled $\mathrm{PH}$ prevalence decreased from $44 \%$ (95\% CI 29-60\%) to $18 \%$ (95\% CI 8-27\%). The overall standardised mean difference in sPAP was 1.12 (95\% CI 0.81-1.44) and 1.62 (95\% CI 1.00-2.23) in cohort and case-series studies respectively indicating a large decrease. The pooled standard mean difference among the younger and older patients were different, 1.25 (95\% CI $0.78-1.71)$ and 0.91 (95\% CI 0.56-1.27), respectively. A high degree of between-study heterogeneity was noted.

Conclusions: Both PH prevalence and mean sPAP decrease after ASD closure. Larger, prospective studies with consistent $\mathrm{PH}$ definitions using the recommended measurement modality are warranted.

This article has supplementary material available from err.ersjournals.com

Provenance: Submitted article, peer reviewed

Received: 15 April 2020 | Accepted after revision: 29 June 2020

Copyright $\odot$ ERS 2020. This article is open access and distributed under the terms of the Creative Commons Attribution Non-Commercial Licence 4.0. 


\section{Introduction}

Congenital heart disease (CHD) is the most common type of birth defect worldwide, accounting for almost one-third of all congenital anomalies [1]. Atrial septal defect (ASD) is the most prevalent adult CHD with an estimated prevalence of 84 per 100000 Canadian adults [2]. ASD is further classified based on anatomic and physiological characteristics with secundum ASD accounting for about $70 \%$ of observed cases [3].

ASDs typically yield a systemic-to-pulmonary (or left-to-right) shunt at the level of the interatrial septum. The direction of blood flow, change in magnitude and degree of shunting is determined by both the size of the defect and the difference in diastolic compliance between the two ventricles [4]. Haemodynamically significant left-to-right shunts can lead to right atrial enlargement, tricuspid valve regurgitation and increased pulmonary blood flow [5]. Pulmonary over-circulation may cause pulmonary vascular remodelling characterised by increased levels of pulmonary vascular resistance (PVR) and changes in pulmonary arterial pressure (PAP) [6]. These changes may result in atrial arrhythmias, right ventricular dilation, right heart failure and/or pulmonary hypertension (PH) [7]. Closure of an ASD is indicated and has been shown to be beneficial in the presence of haemodynamically significant shunts that cause right-sided chamber enlargement and that have led to reduced functional capacity [8]. While the presence of severe $\mathrm{PH}$ is a contraindication for ASD closure, some patients may undergo pre-treatment with $\mathrm{PH}$-specific pharmacotherapy prior to closure, a strategy known as "treat and repair" [9].

As per the 2018 American College of Cardiology (ACC)/American Heart Association (AHA) and 2016 European Society of Cardiology (ESC) and the European Respiratory Society guidelines, $\mathrm{PH}$ has been defined as the haemodynamic state of having a mean PAP (mPAP) of at least $25 \mathrm{mmHg}$ at rest $[8,10]$. The term PH encompassed many different clinical classifications, including pulmonary arterial hypertension $(\mathrm{PAH}) . \mathrm{PAH}$, or pre-capillary $\mathrm{PH}$, was defined as the presence of $\mathrm{PH}$, combined with a pulmonary capillary wedge pressure of $<15 \mathrm{mmHg}$ and PVR of $\geqslant 3 \mathrm{Wood}$ Units [8]. The distinction between $\mathrm{PH}$ and $\mathrm{PAH}$ is important; while all cases of $\mathrm{PAH}$ are forms of $\mathrm{PH}$, the presence of $\mathrm{PH}$ may be due to causes other than PAH. Patients with $\mathrm{PH}$ related to a CHD have increased morbidity and mortality $[11,12]$. In February 2018, the 6th World Symposium on Pulmonary Hypertension (WSPH) Task Force proposed changes to existing definitions; namely, to use a lower mPAP cut-off of $>20 \mathrm{mmHg}$ to define $\mathrm{PH}$ and to use PVR $\geqslant 3$ Wood Units as the only criteria to define pre-capillary PAH [13].

Although ASD closure in adults with normal mPAP and functional capacity is widely accepted as being safe and clinically beneficial, the long-term outcomes and benefits among this population are not clear $[14,15]$. The most recent ACC/AHA guideline stated that adult CHD patients with $\mathrm{PH}$ have a poorer prognosis than those who do not have $\mathrm{PH}$ [8]. There are a set of recommendations for ASD repair in $\mathrm{PH}$ patients depending on the clinical scenario [8]. The clinical presentation of PAH typically falls within a spectrum. At one end there are adults with mild pulmonary vascular disease (PVD) and large ASD shunts; these patients can safely undergo ASD closure [16]. As a general rule, when systolic PAP (sPAP) is less than one-half of systemic blood pressure, and if the pulmonary-to-systemic flow ratio (Qp:Qs) is $>1.5: 1$, ASD closure is recommended [8]. At the other end are patients with irreversible PVD, leading to shunt reversal and cyanosis, a condition known as Eisenmenger syndrome. Eisenmenger physiology does not respond well to closure and its presence is a contraindication to closure. When sPAP is greater than two-thirds systemic and Qp:Qs is <1, the shunt should not be closed [8]. Proper classification of patients within this continuum should be made by a specialist and individual patients should be evaluated on a case-by-case basis [10]. While some studies report that ASD closure in patients with $\mathrm{PH}$ is associated with better long-term outcomes (e.g. reduction of atrial arrhythmias and improved cardiac function capacity of $\mathrm{PH}$ severity) [17], others report that subsets of patients develop $\mathrm{PH}$ or suffer from persistent $\mathrm{PH}$ following closure $[18,19]$. This variability could be partially explained by the effect of the pre-existing $\mathrm{PH}$ severity (e.g. PVR or PAP levels) on observed outcomes.

Historically, open-heart surgical closure had been the standard of care for ASD repair. Since the first noninvasive closure of an ASD performed in 1976 [20], percutaneous closure has grown in popularity for its minimal invasiveness and lower complication rates [21,22]. Starting from the early to mid-2000s, more than $90 \%$ of ASD closures are percutaneous [23], while surgical closure is reserved for primum, sinus venosus, coronary sinus ASDs or secundum ASDs with the presence of other congenital or acquired cardiac conditions or where significant economic limitations make surgical closure more feasible [8]. Differential indication criteria between surgical and percutaneous ASD closure may lead to differences in patient outcomes including those with $\mathrm{PH}$. Where the populations are the same and undergoing both therapies, the long-term outcomes of ASD closure on PH should be similar; however, there are few data to support this hypothesis.

Overall, information on the long-term effects of percutaneous closure among ASD patients with and without a diagnosis of $\mathrm{PH}$ is both limited and variable [8]. The aim of this systematic review and 
meta-analysis was to describe currently used $\mathrm{PH}$ definitions, evaluate the prevalence of $\mathrm{PH}$ and the effect of $\mathrm{PH}$ on outcomes in ASD patients undergoing percutaneous closure.

\section{Methods}

Protocol and registration

The reporting of this systematic review followed the Preferred Reporting Items for Systematic Reviews and Meta-Analyses (PRISMA) statement [24].

\section{Eligibility criteria}

We included studies that reported the prevalence of $\mathrm{PH}$ (based on study-specific definitions) and/or mean PAP (mPAP or sPAP) levels at baseline and after percutaneous closure of ASD in adult patients aged $>18$ years. Studies with a mixed patient population were excluded if they did not provide separate data for adult patients with percutaneous ASD closure and only reported pooled data (e.g. a surgical cohort, paediatric population, patients undergoing closure for other congenital heart diseases such as ventricular septal defect, atrioventricular septal defect or patent foramen ovale).

Clinical outcomes of interest following ASD closure were not limited and included any one of the following: successful closure, survival, New York Heart Association (NYHA) functional class, cardiovascular outcomes (e.g. stroke, myocardial infarction, and heart or lung transplant) and device-related complications. As the cut-offs for pulmonary artery pressure for $\mathrm{PH}$ diagnosis were not defined consistently, we also reported the definitions, PH measurement methods and cut-offs that were used by the authors of each study.

We included case series, cohort studies and randomised control trials of any follow-up duration. Single case studies, case series with fewer than five patients and case-control studies were excluded. We excluded studies that used simulated datasets, reviews, editorials, clinical guidelines, as well as nonhuman, non-English studies and conference abstracts.

\section{Information sources}

Eligible studies were identified through a search of three interdisciplinary databases including Ovid MEDLINE, EMBASE and the Cochrane Database of Systematic Reviews from their inception dates to 13 July 2019.

\section{Search strategy}

Our peer-reviewed search strategy was guided by an information specialist experienced in this area. The search syntax combined terms for "atrial septal defect", "percutaneous closure" and "pulmonary hypertension" (table S1 for the search strategy in Ovid MEDLINE). Citations were imported and de-duplicated in a citation manager software.

\section{Study selection}

Records identified through our search were screened for potential inclusion in our systematic review using the Covidence online tool [25]. Two reviewers (S. Akseer and V. Vishwanath) independently screened the titles and abstracts for inclusion. If there was an uncertainty based on the title and abstract of a reference, it was passed through to full-text screening. All discrepancies were resolved by reaching a consensus with the two reviewers. Reasons for exclusion were recorded in Covidence.

\section{Data collection and items}

Two reviewers in pairs (S. Akseer, V. Vishwanath and B. Hobbes), independently extracted data from included full-text studies using a standardised data extraction form in Excel spreadsheets. Data extraction domains included general study characteristics (e.g. time periods, study design), baseline patient characteristics before ASD closure (e.g. age, sex, PH definition and prevalence, echocardiographic data, ASD size, NYHA functional class), follow-up data after ASD closure (e.g. mean follow-up time, $\mathrm{PH}$ prevalence, echocardiographic data), any vasodilator medications for $\mathrm{PH}$ before and after the procedure and all short- and long-term outcomes reported.

\section{Quality assessment}

Methodological quality assessment of the included studies was completed using the Joanna Briggs Institute Critical Appraisal checklists for cohort and case-series studies [26]. We adhered to the explanations and definitions provided in the tool and modified the components to make them more specific to our study population when relevant (table S2). Measurement of the exposure and outcome was considered to be valid when the gold standard of right heart catheterisation (RHC) was used [8]. We assumed that a dropout rate $>20 \%$ can be a potential threat to internal validity. 
Data analysis and synthesis of results

We undertook an initial descriptive analysis of the included studies by summarising information on study and patient characteristics (e.g. demographics, ASD information, PH diagnostics and echocardiographic data before percutaneous closure and outcomes after follow-up). For studies that included PH prevalence before and after ASD closure, we descriptively plotted these values.

Meta-analysis was performed if outcomes of interest were reported in similar patient populations and study designs. We used the metafor package in $\mathrm{R}$ statistical software for meta-analysis [27]. A meta-analysis of $\mathrm{PH}$ prevalence before and after ASD closure was completed for studies that reported relevant data. We calculated a combined prevalence value with associated 95\% CI using the DerSimonianLaird random effects model [28]. If the individual study estimates for prevalence were between $20 \%$ and $80 \%$, then the data were likely to be normally distributed [29]. We analysed the heterogeneity of the prevalence of $\mathrm{PH}$ between studies using the $\mathrm{I}^{2}$ statistic [30].

We measured the effect of percutaneous ASD closure on mean sPAP by calculating the standardised mean differences (SMD) before and after closure. We used SMD to estimate the effect size of percutaneous closure on mean sPAP values within studies and to determine a combined pooled effect, for cohort studies and case series separately. We also completed an age-stratified analysis for SMD among younger $(<60$ years old) and older ( $>60$ years old) patient populations.

\section{Results}

Study selection

Our search strategy identified 1423 potentially relevant records (figure S1). After removing duplicates, a total of 1138 records were title and abstract screened. We retrieved 67 studies for a full-text review and excluded 52 studies. The most common reasons for exclusion were poster presentations and/or conference proceedings $(n=13)$, using surgical closure $(n=11)$, and having only pooled results from paediatric and adult populations $(\mathrm{n}=10)$. We included a total of 15 studies in this review that met our study eligibility criteria $[9,31-44]$.

\section{Systematic review}

We identified a recent systematic review with a potential overlap with our review. A systematic review by ZWIINENBURG et al. [45] reported the prevalence of PAH among patients undergoing ASD closure in 30 studies published before March 2017. The review, however, evaluated surgical and percutaneous closure populations together. We limited our inclusion to patients undergoing percutaneous closure considering the current differences in indication criteria for each approach. ZwIJNENBURG et al. [45] included studies that reported right ventricular systolic pressure (RVSP) and used the values as proxy for SPAP (i.e. used the two measures interchangeably in their analyses). While RVSP can be used to approximate sPAP, there must be evidence of no right ventricular or pulmonary tract obstruction [46]. The discordance between these two measures is especially pronounced among patients with $\mathrm{PH}$ [47]. For these reasons, we refrained from seeking studies that reported only RVSP and using that as a proxy for sPAP. We did, however, include studies that reported sPAP measures derived from tricuspid regurgitation jet velocity using the Bernoulli equation. The review by Zwisnenburg et al. [45] also combined all forms of PH under PAH, however the importance of this distinction and additional haemodynamic parameters required for its identification have been well emphasised in the AHA guidelines [8], ESC guidelines [10] and by the recent WSPH Task Force [13]. In our review we maintained the two as distinct forms of $\mathrm{PH}$ and specified when applicable. Finally, the analyses by Zwijnenburg et al. [45] were limited to descriptive summaries and no meta-analysis was performed. In our review we present both a descriptive summary and a formal meta-analysis.

\section{Study characteristics}

The 15 included studies represented 12 different countries including three from Canada, two from Japan and one study for each of the following countries: the Netherlands, Germany, India, Spain, Austria, Belgium, Italy, Taiwan, China and Israel. Six of the included studies were case series and nine were cohort (four retrospective and five prospective) studies (table 1). The studies represented a total of 1073 adult patients undergoing percutaneous ASD closure. Sample sizes among studies ranged from 6 to 215 patients before ASD closure. The mean age was between 29 and 67 years, with a range from 20 to 81 years. On average, females comprised $61.5-87.0 \%$ of the study samples. Mean follow-up time varied from 3 to 60 months.

\section{PH measurement and definitions}

$12(80 \%)$ studies used transthoracic (TTE) or transoesophageal echocardiography (TEE) and four studies used the gold standard, RHC $[9,33,39,44]$. The definitions for PH varied among studies (table 1). Nine studies used sPAP values to define $\mathrm{PH}$ with cut-off values $\geqslant 35 \mathrm{mmHg}[31,41], \geqslant 40 \mathrm{mmHg}[32,35,38$, 
TABLE 1 Study and patient characteristics at baseline, before atrial septal defect (ASD) closure

\begin{tabular}{|c|c|c|c|c|c|c|c|c|c|c|c|}
\hline First author [ref]. & Study design & $\begin{array}{l}\text { Time } \\
\text { period }\end{array}$ & $\begin{array}{l}\text { Sample } \\
\text { size } n\end{array}$ & Age years & Female & $\begin{array}{l}\text { ASD diameter } \\
\mathrm{mm}\end{array}$ & $\begin{array}{c}\text { NYHA } \\
\text { class III-IV }\end{array}$ & $\begin{array}{l}\text { PH assessment } \\
\text { method }\end{array}$ & $\begin{array}{l}\text { PH measure and } \\
\text { cut-offs } \mathrm{mmHg}\end{array}$ & Mean sPAP $\mathrm{mmHg}$ & $\begin{array}{c}\mathrm{PH} \\
\text { prevalence }\end{array}$ \\
\hline Veldtman [31] & $\begin{array}{l}\text { Retrospective } \\
\text { cohort }\end{array}$ & 1997-1999 & 40 & $38(20-71)$ & 75 & $13 \pm 4$ & 5 & TEE & sPAP >35 & NR & 62 \\
\hline DE Lezo [32] & Case series & NR & 29 & $56 \pm 14$ & 83 & $26 \pm 7$ & 48 & TTE/TEE & $\mathrm{sPAP} \geqslant 40$ & $64 \pm 23$ & 100 \\
\hline BRUCH [33] & Case series & NR & 15 & $66(48-77)$ & 66.6 & $22.7 \pm 7.0(9-34)$ & 60 & TTE/RHC & mPAP $>25$ & $58.3 \pm 15$ & 100 \\
\hline BALINT $[34]^{\#, \pi}$ & Case series & 1999-2004 & 54 & $59 \pm 15$ & 76 & $18 \pm 7$ & 41 & TTE/TEE & $\begin{array}{l}\text { sPAP } 40-49 \text { (mild), } \\
50-59 \text { (moderate), } \\
\geqslant 60 \text { (severe) }\end{array}$ & $58 \pm 10$ & 100 \\
\hline YoNG [35] $]^{\#, \pi}$ & $\begin{array}{l}\text { Prospective } \\
\text { cohort }\end{array}$ & 1999-2006 & 215 & $54 \pm 16$ & 73 & $19 \pm 6$ & 19 & TTE & $\mathrm{SPAP} \geqslant 40$ & $\begin{array}{l}\text { Median (IQR) } 30.0 \\
(25.0-36.0)\end{array}$ & 50.2 \\
\hline YALONETSKY [36] $^{\#}$ & $\begin{array}{l}\text { Retrospective } \\
\text { cohort }\end{array}$ & 1998-NR & 23 & & & & NR & TTE & sPAP cut-off NR & & NR \\
\hline Age $40-60$ years & & & & $52 \pm 6$ & 74 & $19 \pm 5$ & & & & $39 \pm 7.7$ & \\
\hline Age $60+$ years & & & & $67 \pm 5$ & 70 & $18 \pm 5$ & & & & $53 \pm 16.2$ & \\
\hline ALtindAg [37] & $\begin{array}{l}\text { Retrospective } \\
\text { cohort }\end{array}$ & 1999-2008 & 47 & $\begin{array}{l}58 \pm 13 \\
(40-79)\end{array}$ & 79 & $N R$ & 43 & TTE/TEE & NR & NR & 62 \\
\hline HUMENBERGER [38] $]^{\#, \pi}$ & $\begin{array}{l}\text { Prospective } \\
\text { cohort }\end{array}$ & NR & & & & & & TTE/TEE & $\mathrm{sPAP} \geqslant 40$ & & NR \\
\hline Age $<40$ years & & & 78 & $29 \pm 6.7$ & 61.5 & $\begin{array}{l}\text { Median (IQR) } \\
23(29-26)\end{array}$ & 1.3 & & & $31 \pm 7$ & \\
\hline Age $40-60$ years & & & 84 & $50 \pm 5.6$ & 65.5 & $\begin{array}{l}\text { Median (IQR) } \\
22 \text { (17.5-26.5) }\end{array}$ & 3.8 & & & $37 \pm 10$ & \\
\hline Age $>60$ years & & & 74 & $71 \pm 6.1$ & 82.4 & $\begin{array}{l}\text { Median (IQR) } \\
22.5(20-28)\end{array}$ & 41.4 & & & $53 \pm 17$ & \\
\hline Huang [39] & $\begin{array}{l}\text { Retrospective } \\
\text { cohort }\end{array}$ & $2007-2010$ & 15 & $32.3 \pm 12.8$ & 73.3 & NR & $N R$ & $\mathrm{RHC}$ & $\begin{array}{c}\text { sPAP } \geqslant 60 \text { (severe } \\
\text { PAH) }\end{array}$ & $51.6 \pm 9.4$ & 100 \\
\hline KEFER $[40]^{\#}$ & $\begin{array}{l}\text { Prospective } \\
\text { cohort }\end{array}$ & 1999-2009 & 112 & $46 \pm 17$ & 71 & $\begin{array}{c}\mathrm{PH}: 22 \pm 5 \\
\text { no } \mathrm{PH}: 18 \pm 6\end{array}$ & 31 & TTE & sPAP $>40$ & $47 \pm 7$ & 28 \\
\hline NakaGaWa $[41]^{1 \# \#}$ & $\begin{array}{c}\text { Prospective } \\
\text { cohort }\end{array}$ & $2005-2010$ & 30 & $\begin{array}{l}75.8 \pm 3.8 \\
(70-85)\end{array}$ & 66.6 & $20.3 \pm 6.4$ & 35 & TEE & $m P A P \geqslant 25$ & $35.6 \pm 11.8$ & 53 \\
\hline MANGIAFICO $[42]^{\#}$ & $\begin{array}{l}\text { Prospective } \\
\text { cohort }\end{array}$ & 2008-2011 & & & NR & NR & & TTE & sPAP cut-off NR & & NR \\
\hline Age $<40$ years & & & 10 & $29 \pm 7.3$ & & & 0 & & & $35.1 \pm 6.6$ & \\
\hline Age $>40$ years & & & 20 & $58 \pm 11$ & & & 0 & & & $41.2 \pm 6.4$ & \\
\hline AKAGI [9]" & Case series & 2006-2014 & & & & & & $\mathrm{RHC}$ & & & \\
\hline PHM group 1 & & & 8 & $37 \pm 15$ & 100 & $22 \pm 7$ & 88 & & $\mathrm{sPAP} \geqslant 60$ & $60 \pm 11$ & 100 \\
\hline Non-PHM group 2 & & & 14 & $66 \pm 13$ & 71 & $23 \pm 8$ & 21 & & $m P A P \geqslant 25$ & $58 \pm 17$ & \\
\hline WANG [43] & $\begin{array}{l}\text { Retrospective } \\
\text { cohort }\end{array}$ & 2000-2009 & 179 & $\begin{array}{l}\text { Median } \\
\text { (IQR) } 53 \\
\text { (40-81) }\end{array}$ & 75.4 & NR & 8.9 & TEE & $\mathrm{SPAP} \geqslant 40$ & $44.8 \pm 22.2$ & 24 \\
\hline DALVI [44] & Case series & 2009-2014 & 6 & $29 \pm 8.89$ & 83.3 & $28 \pm 2.09$ & 0 & $\mathrm{RHC}$ & $m P A P \geqslant 25$ & $102.6 \pm 11.5$ & 100 \\
\hline
\end{tabular}

Data are presented as mean (range), \%, mean \pm SD or mean \pm SD (range), unless otherwise stated. NYHA: New York Heart Association; PH: pulmonary hypertension; sPAP: systolic pulmonary artery pressure; TEE: transoesophageal echocardiography; TTE: transthoracic echocardiography; RHC: right heart catheterisation; NR: not reported; mPAP: mean pulmonary artery pressure; PAH: pulmonary arterial hypertension; PHM: pulmonary hypertension medication. \#: study-reported sPAP values derived from right ventricular systolic pressure; १: study-reported values for PAH. 
$40,43,44]$ or $\geqslant 60 \mathrm{mmHg}$ [39]. One study defined mild (sPAP=40-49), moderate (sPAP=50-59) and severe (sPAP $\geqslant 60) \mathrm{PH}$ levels [34]. One study used mPAP $>25 \mathrm{mmHg}$ [33] and another used either sPAP $\geqslant 60$ or $\mathrm{mPAP} \geqslant 25 \mathrm{mmHg}$ to define $\mathrm{PH}$ [9]. Three studies did not report the cut-off values [36, 37, 42]. From 15 studies, 6 (40\%) studies reported measuring PAH [9, 34, 35, 38, 39, 41], although not all of these studies mentioned measuring capillary wedge pressure explicitly. None of the studies used mPAP $>20 \mathrm{mmHg}$ as a cut-off value to define $\mathrm{PH}$.

Five studies reported PH prevalence before the procedure and at follow-up after the procedure [31, 35, 37, 40, 43]. 12 studies reported mean sPAP before and after closure (table 2) [9, 32-36, 38-42, 44]. The case series exclusively enrolled patient populations with an existing diagnosis of $\mathrm{PH}[9,32-34,39,44]$. All studies reported the mean ASD diameter and method of $\mathrm{PH}$ assessment. Data on NYHA functional class were available for 13 of the included studies [9, 31-35, 37, 38, 40-44] and all 13 studies reported an improvement in in NYHA functional class following closure. The proportion of patients in class III or IV ranged from $1.3 \%$ to $88 \%$ before closure and $0-5 \%$ after closure.

\section{Quality assessment}

The results of the quality appraisal of included cohort studies is presented in figure S2. All cohort studies recruited patients with and without $\mathrm{PH}$ from the same population and all patients underwent $\mathrm{PH}$ measurement. Three studies used RHC to assess for PH before and after closure $[9,39,44]$. One study used TTE at baseline and switched to RHC at follow-up [33]. 8 (89\%) cohort studies had $>20 \%$ loss to follow-up. Reasons for loss to follow-up were explained in 6 (67\%) studies, and strategies to deal with loss to follow-up were applied in $3(33 \%)$ studies.

The quality assessment of six case series studies is shown in figure S2b. All studies that used RHC were case series. One of the included case series used RHC to collect patient data at baseline, then switched to TTE at follow-up.

TABLE 2 Study-reported outcomes at follow-up

\begin{tabular}{|c|c|c|c|c|c|c|c|}
\hline First author [ref.] & $\begin{array}{l}\text { Sample } \\
\text { size } \mathrm{n}\end{array}$ & $\begin{array}{l}\text { Mean follow-up } \\
\text { time months }\end{array}$ & $\begin{array}{c}\mathrm{PH} \\
\text { assessment } \\
\text { method }\end{array}$ & $\begin{array}{l}\text { Mean sPAP after closure } \\
\qquad \mathrm{mmHg}\end{array}$ & $\begin{array}{c}\text { Mean sPAP } \\
\text { reduction } \mathrm{mmHg}\end{array}$ & $\begin{array}{c}\mathrm{PH} \\
\text { prevalence }\end{array}$ & $\begin{array}{l}\text { NYHA } \\
\text { class } \\
\text { III-IV }\end{array}$ \\
\hline DE Lezo [32] & 28 & $21 \pm 14$ & TTE & $34 \pm 11$ & $14^{\#}$ & 100 & 0 \\
\hline BRUCH [33] & 13 & $10 \pm 4$ & $\mathrm{RHC}$ & $49.9 \pm 17.8$ & NR & 92 & 0 \\
\hline BALINT [34]" & 39 & $31 \pm 15$ & TTE/TEE & $44 \pm 16$ & $14^{\#}$ & NR & 20 \\
\hline YALONETSKY $[60]$ & NR & NR (1-12) & TTE & & NR & NR & NR \\
\hline Age $40-60$ years & & & & 26 & & & \\
\hline Age $>60$ years & & & & 33.5 & & & \\
\hline ALtindag [37] & 41 & $15 \pm 15$ & TTE/TEE & NR & NR & 38 & 5 \\
\hline HumenBerger [38 $]^{\top \pi}$ & & $28 \pm 19$ & TTE & & & NR & \\
\hline Age $<40$ years & 75 & & & $26 \pm 5$ & $5 \pm 8$ & & 0 \\
\hline NaKagaWA $[41]^{\top 1}$ & 27 & $19.1 \pm 11.3$ & TEE & $27.2 \pm 7.3$ & NR & NR & 4 \\
\hline MANGIAFICO [42] & & NR (1-12) & TTE & & & NR & \\
\hline Age $<40$ years & 10 & & & $28 \pm 2.8$ & $7.1^{\#}$ & & 0 \\
\hline Age $>40$ years & 20 & & & $28.4 \pm 6.5$ & $12.8^{\#}$ & & 0 \\
\hline AKAGI [9] & & & TTE & & NR & NR & \\
\hline PHM group 1 & 8 & $19 \pm 27(3-83)$ & & $40 \pm 9$ & & & 0 \\
\hline non-PHM group 2 & 14 & $19 \pm 16(4-61)$ & & $38 \pm 10$ & & & 0 \\
\hline WANG [43] & 176 & $45.6 \pm 25.2$ & TEE & NR & NR & 7 & 1.7 \\
\hline DaLvi [44] & 4 & $39.5 \pm 8.5$ & $\mathrm{RHC}$ & $55.7 \pm 9.2$ & $12.8^{\#}$ & NR & 0 \\
\hline
\end{tabular}

Data are presented as mean $\pm \mathrm{SD}$, mean (range) or \%, unless otherwise stated. PH: pulmonary hypertension; sPAP: systolic pulmonary artery pressure; NYHA: New York Heart Association; PHM: pulmonary hypertension medication; NR: not reported; TTE: transthoracic echocardiography; RHC: right heart catheterisation; TEE: transoesophageal echocardiography. \#: when mean sPAP reductions were not reported, we calculated (mean SPAP before closure $(\mathrm{mmHg})$ ) - (mean SPAP after closure (mmHg)); ${ }^{\Uparrow}$ : study reported values for pulmonary arterial hypertension; ${ }^{+}$: study reported mean values as mPAP. 


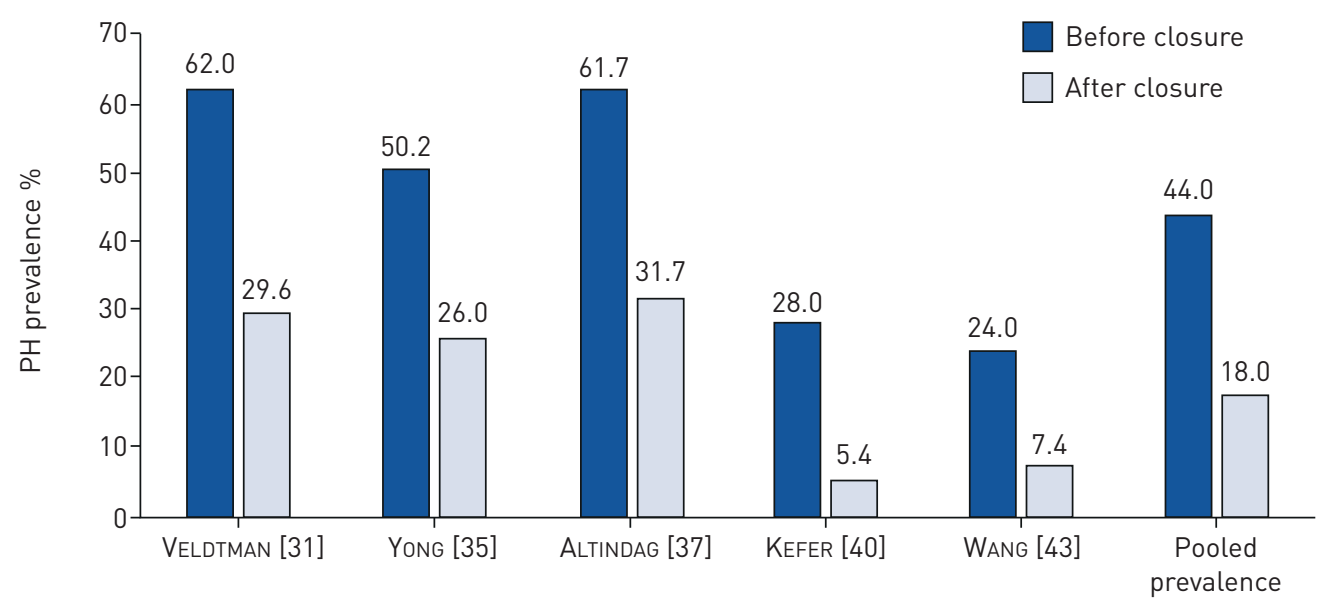

FIGURE 1 Pulmonary hypertension (PH) prevalence before and after atrial septal defect closure presented in each study.

Prevalence of PH before and after closure

Five cohort studies reported $\mathrm{PH}$ prevalence before and after ASD closure using study-specific mean PAP or mean sPAP cut-offs $[27,31,33,36,40]$. The prevalence of $\mathrm{PH}$ varied from $24 \%$ to $62 \%$ before ASD closure and from $5 \%$ to $31 \%$ after ASD closure (figure 1). The reported prevalence estimates among the included studies were between $20 \%$ and $80 \%$, as such, we assumed our data were normally distributed and did not apply a transformation for potential outliers when meta analysing.

The pooled PH prevalence was 44\% (95\% CI 29-60\%) before closure (figure 2a) and 18\% (95\% CI 8-27\%) after closure (figure 2b). The between-study heterogeneity was high $\left(\mathrm{I}^{2}=93 \%\right.$ and $91 \%$, respectively $(\mathrm{p}<0.01))$.

\section{Mean SPAP before and after ASD closure}

The mean follow-up time in the studies ranged from 10 to 60 months. A total of 12 studies reported mean sPAP before and after closure $[9,32-36,38-42,44]$. Of the 12 studies, three reported mean sPAP values stratified by age $[36,38,42]$, while one study reported outcomes by $\mathrm{PH}$-specific medication groups (i.e. patients taking $\mathrm{PH}$-specific medications and patients not taking $\mathrm{PH}$-specific medications) [9].

$\begin{array}{lccc}\text { a) } & \text { Cases } & \text { Total } & \text { Prevalence }(95 \% \mathrm{CI}) \\ \text { VeLDTMAN [31] } & 23 & 37 & 0.62(0.45-0.78) \\ \text { YoNG [35] } & 108 & 215 & 0.50(0.43-0.57) \\ \text { ALtINDAG [37] } & 29 & 47 & 0.62(0.46-0.75) \\ \text { KEFER [40] } & 31 & 112 & 0.28(0.20-0.37) \\ \text { WANG [43] } & 43 & 179 & 0.24(0.18-0.31) \\ \text { Combined prevalence } & & 0.44(0.29-0.59) \\ \text { Heterogeneity: }{ }^{2}=93 \%, \tau^{2}=0.0271, \chi_{4}^{2}=58.34(p<0.01)\end{array}$

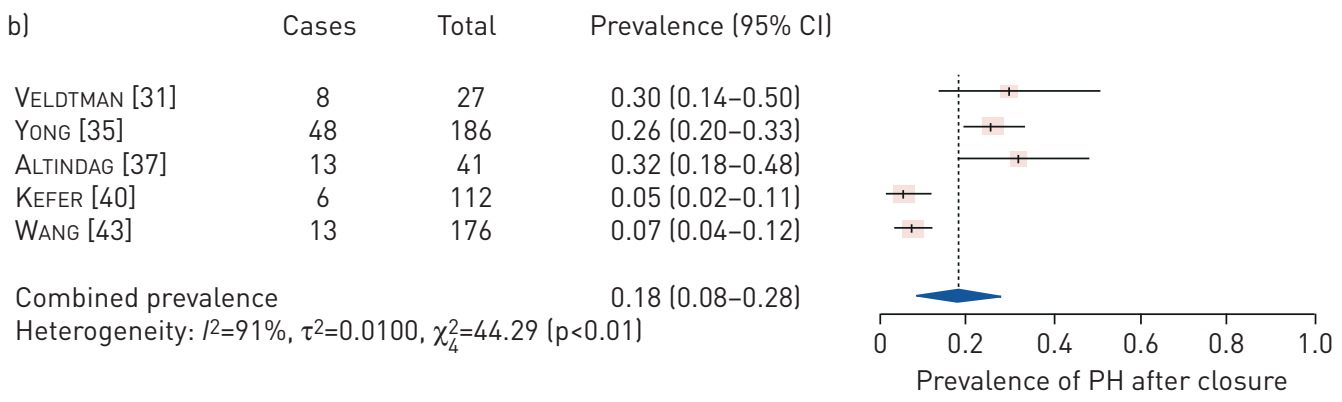

FIGURE 2 The pooled pulmonary hypertension (PH) prevalence a) before and b) after atrial septal defect closure in cohort studies. 
We calculated the SMD for two different types of patient populations: cohort studies that enrolled a general patient population with and without $\mathrm{PH}$ (figure 3a) [35, 36, 38, 40-42] and case-series studies that exclusively enrolled patients with $\mathrm{PH}[9,32-34,39,44]$ (figure 3b). In cohort studies, the mean sPAP ranged from 30 to $53 \mathrm{mmHg}$ before closure and from 25 to $43 \mathrm{mmHg}$ after closure. All cohort studies showed a reduction in sPAP following closure, with a positive SMD of 1.12 (95\% CI $0.81-1.44)$. In case-series studies, the mean sPAP ranged from 51.6 to $102.6 \mathrm{mmHg}$ before closure and from 21 to $55.7 \mathrm{mmHg}$ after closure. All case series reported a reduction in sPAP following ASD closure with a pooled SMD of 1.62 (95\% CI 1.00- 2.23). Between-study heterogeneity was high in both sets of analyses $\left(\mathrm{I}^{2}=83 \%\right.$ in cohort and $71 \%$ in case series).

For cohort studies we also completed exploratory age-stratified subgroup analyses for mean sPAP by analysing the studies with younger ( $\leqslant 60$ years old) and older patient populations ( $>60$ years old) separately. The pooled SMD among the younger and older patients was 1.25 (95\% CI 0.78-1.71) and 0.91 (95\% CI 0.56-1.27), respectively (figure 4). A small improvement in between-study heterogeneity was observed.

\section{Long-term outcomes}

The reporting of long-term outcomes was limited and not consistent between the studies in term of types of outcomes and length of follow-up (table S3). None of the included studies compared the outcomes of ASD closure between patients with and without $\mathrm{PH}$.

\section{Discussion}

To our knowledge this is the first systematic review and meta-analysis exclusively assessing the effects of percutaneous ASD closure on PH in adults. We included a total of 15 studies that reported baseline and follow-up data on $\mathrm{PH}$ in this patient population. We found that the $\mathrm{PH}$ prevalence as well as mean sPAP decreased following ASD closure among all studies, irrespective of age. The magnitude of mean sPAP reduction was greater amongst case series studies which could potentially suggest that patients with high $\mathrm{PH}$ may benefit the most from the intervention. A high degree of heterogeneity was observed between the studies and long-term outcomes were reported inconsistently.

\section{Quality assessment}

The critical appraisal of the methodological quality of studies revealed areas of concerns. Case series were relatively more rigorously done than the cohort studies, perhaps due a more defined approach to case selection. Overall, only three studies used $\mathrm{RHC}$ for $\mathrm{PH}$ assessment contributing to variability in $\mathrm{PH}$ prevalence estimates, and therefore, heterogeneity between the studies. Another area of concern was the adequacy of follow-up with roughly half of the included cohort studies having $>20 \%$ loss to follow-up of their original sample. Depending on the reasons of loss to follow-up, the true effect of ASD closure on PH measures and other outcomes can be over- or underestimated.

\section{Measurement of $\mathrm{PH}$}

Although RHC is the current gold standard for haemodynamic data collection, it is costly, invasive and less desirable for patients. Thus, echocardiographic methods were predominantly used in included studies. Echocardiography may suggest the presence of $\mathrm{PH}$ by estimating the RVSP; however, it cannot differentiate between the two types of $\mathrm{PH}$ associated with ASD, $\mathrm{PH}$ (mPAP $\geqslant 25 \mathrm{mmHg}$ and PVR $<3$ Wood Units) and PAH (mPAP $\geqslant 25 \mathrm{mmHg}$ and PVR $\geqslant 3$ Wood Units) [8, 10]. A PH diagnosis using RHC is necessary to distinguish $\mathrm{PH}$ subtypes and therefore, we limited our use of the term PAH. Furthermore, echocardiographic studies used variable cut-offs for $\mathrm{PH}$ definition and diagnosis ranging from $\mathrm{mPAP}>25 \mathrm{mmHg}$ to $\mathrm{sPAP}>35,40,50$ or $>60 \mathrm{mmHg}$. Although there is an established strong linear relationship between $\mathrm{mPAP}$ and $\mathrm{sPAP}$, the proposed formula of $\mathrm{mPAP}=0.61 \mathrm{sPAP}+2 \mathrm{mmHg}$ to link them is based on RHC measures only [48], which do not consider the additional variability introduced by using TEE or TTE [49]. For consistency and due to the limited reporting of a few studies, all values reported in this review were for mean sPAP in patients. We contemplate that some portion of between-study heterogeneity that we observed was due to differences in $\mathrm{PH}$ measurement methods and definitions. Future studies should use guideline recommendations to measure and define $\mathrm{PH}$ to enhance the comparability between the studies and validity of findings.

\section{Definition of $\mathrm{PH}$}

The ESC clinical guidelines for $\mathrm{PH}$ and the AHA/ACC guidelines for CHD proposed the same case definitions and cut-offs for $\mathrm{PH}$ and $\mathrm{PAH}$; $\mathrm{PH}$ is defined as $\mathrm{mPAP} \geqslant 25 \mathrm{mmHg}$ and $\mathrm{PAH}$ is defined as $\mathrm{mPAP} \geqslant 25 \mathrm{mmHg}$ combined with a pulmonary capillary wedge pressure $\leqslant 15 \mathrm{mmHg}$ and PVR of $\geqslant 3$ Wood Units $[8,10]$. As we observed, these definitions were not consistently applied in the current 


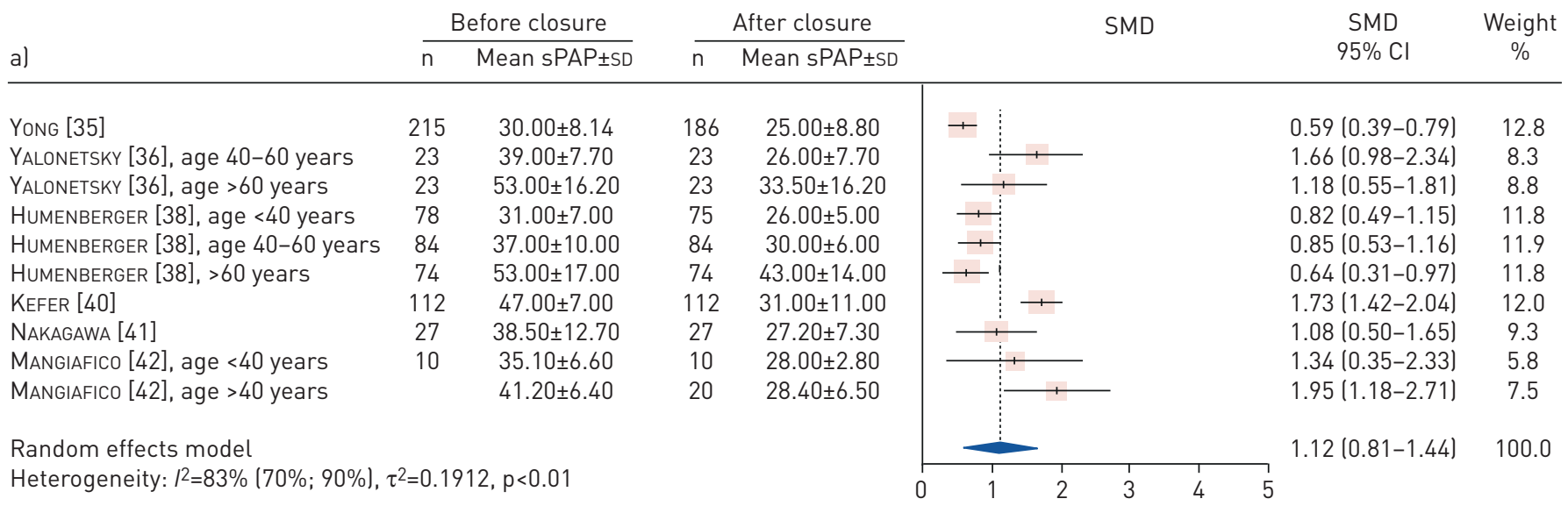

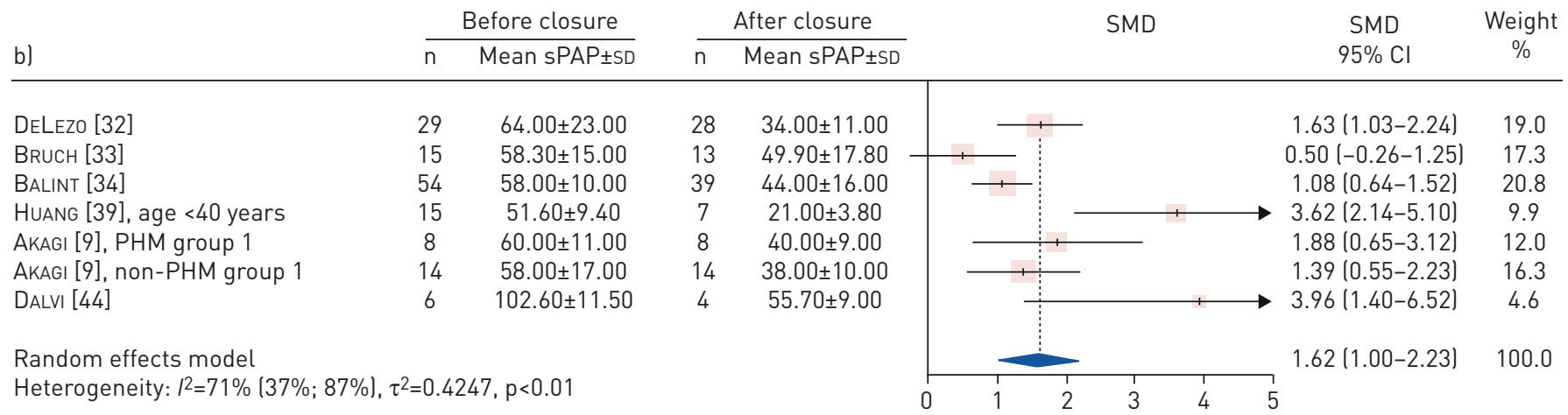

FIGURE 3 Standardised mean difference in mean systolic pulmonary arterial pressure (sPAP) before and after atrial septal defect closure in a) cohort studies and b) case series. SMD: standard mean difference; PHM: pulmonary hypertension medication.

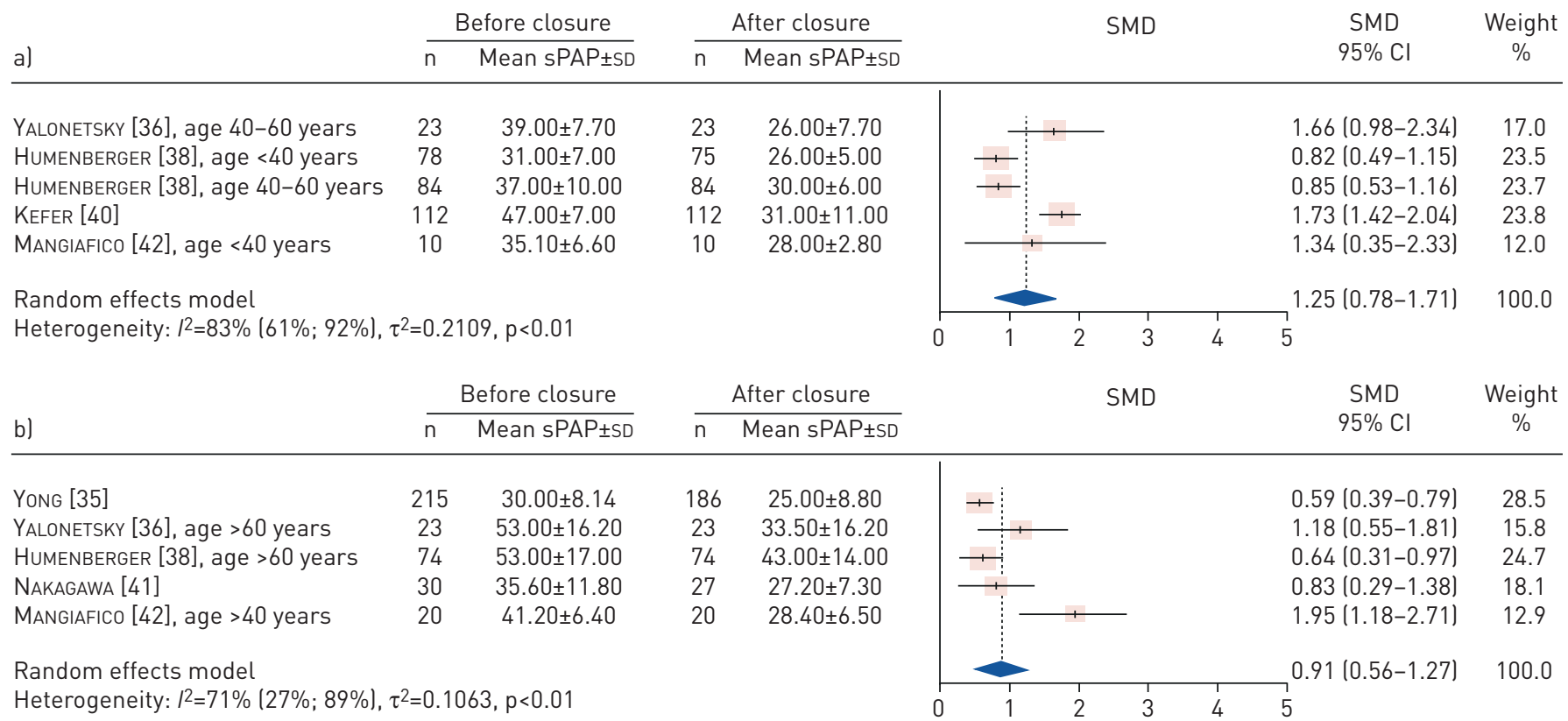

FIGURE 4 Standardised mean difference in mean systolic pulmonary arterial pressure (sPAP) before and after atrial septal defect closure among cohort studies in al younger patients and b) older patients. 
literature. For example, as stated, six studies reported results for PAH; however, only two studies applied the current guideline definition for PAH. This could be partially explained by the fact that $\mathrm{PH}$ guideline definitions require RHC to retrieve haemodynamic parameters, while most included studies used echocardiographic methods. The latter is a more practical approach if one wants to use the same $\mathrm{PH}$ definition before and after the procedure without performing the invasive RHC twice. The recent WSPH redefined $\mathrm{PH}$ as $\mathrm{mPAP}>20 \mathrm{mmHg}$ and $\mathrm{PAH}$ as $\mathrm{mPAP}>20 \mathrm{mmHg}$ with PVR of $\geqslant 3$ Wood Units [13]; these changes will be reflected in the new ESC guidelines [13]. The new PH definition and cut-off is predicted to increase the $\mathrm{PH}$ population estimates by $<10 \%$ [50]. To accelerate research in this area and to investigate the effect of this change on real-world patient outcomes, authors should start consistently applying the new $\mathrm{PH}$ definition. One way to achieve this would be the development of a validated formula to link the RHC-based PH definition to an echocardiography-based definition.

\section{PH prevalence before and after ASD closure}

We found that the combined $\mathrm{PH}$ prevalence declined from $44 \%$ at baseline to $18 \%$ following the closure within a mean follow-up range of 15 to 60 months. PH prevalence widely varied among the included study populations. A Dutch study following 882 ASD patients for a mean follow-up of 4.2 years showed similar changes in $\mathrm{PAH}$ prevalence from $35 \%$ before closure to $13 \%$ after closure $[11,51]$. In our review, studies that reported a high PH prevalence after closure had smaller sample sizes. Our meta-analyses also showed a high degree of heterogeneity between the studies. Therefore, the results should be interpreted with caution considering the small sample size of existing $\mathrm{PH}$ prevalence studies. It is also important to note that we are using the term prevalence to report the proportion of $\mathrm{PH}$ following percutaneous closure. However, in absence of patient level data, we cannot differentiate whether these are newly developed incident cases of $\mathrm{PH}$ or cases of persistent $\mathrm{PH}$. This becomes necessary when determining attributing factors associated with the development or persistence of $\mathrm{PH}$.

\section{Mean SPAP before and after ASD closure}

To ensure that the change we observed in mean SPAP values could be attributed to ASD closure and not to individual patient characteristics, we chose to separate our analyses by patient population and age. When we separated our meta-analyses by study design, we saw less heterogeneity among case-series studies compared to cohort studies. We found that patients in the case series with a higher mean sPAP at baseline demonstrated greater differences in sPAP in follow-up. Case-series studies also showed a greater combined mean sPAP reduction than cohort studies. This could be because patients with a higher baseline sPAP (extreme cases) have more room for improvement or regression to the mean. Although all studies reported an overall reduction in mean sPAP, two studies mentioned that a small proportion of individual patients did not show a decrease in sPAP $[9,34]$. One study reported outcomes separately for patients taking $\mathrm{PH}$-specific medications who showed better improvement in SPAP following closure compared to patients not on PH medications [9]. The study concluded that the use of $\mathrm{PH}$ medications can increase the magnitude of sPAP reduction following ASD closure.

All cohort studies that provided age-stratified mean sPAP reported reductions irrespective of age category. However, the magnitude in SMD reductions was typically larger in cohorts that had a lower mean age. As such, we chose to analyse age cohorts separately and explore this association. Previous literature has indicated an association between age and $\mathrm{PH}$ [52-54]. With the current data from this review, we distinguished young patients from older patients by applying an age cut-off of 60 years. We categorised each study population as young or old based on their mean \pm SD age at baseline, falling either above or below 60 years. For the study by Yong et al. [35], which had a mean \pm sD age of $54 \pm 16$ years, we completed a series of sensitivity analyses by adding this study to the younger cohort, older cohort or removing it, respectively. We ultimately added it to the older population age group based on lowest heterogeneity.

Current guidelines indicate percutaneous closure of ASD is beneficial at any age [54]. We found positive mean sPAP reductions following ASD closure within age-stratified cohorts, meaning that percutaneous closure of an ASD is beneficial in lowering mean sPAP levels, at any age. These results are consistent with the findings of other studies $[36,38,42]$. In our meta-analysis we saw a decrease in mean sPAP reduction beyond the age of 60 years in both of the age-stratified cohorts. Although percutaneous closure lowers mean sPAP levels in all age cohorts, the magnitude of this effectiveness may decrease with older age.

\section{Conclusions}

In conclusion, we found that the pooled prevalence of $\mathrm{PH}$ and mean sPAP among patients who were eligible and underwent ASD closure decreased after the procedure. The decrease was observed in all age groups, to a different degree. Long-term follow-up studies are needed to observe the effect of change in $\mathrm{PH}$ on outcomes. A more consistent approach to diagnose and define $\mathrm{PH}$ is warranted to enhance the 
comparisons between studies. Prospective studies should use the new $\mathrm{PH}$ diagnostic criteria and evaluate the impact of this change on patient outcomes.

Acknowledgements: We are grateful to Ashley Farrell (Library \& Information Services, Toronto General Hospital, Toronto, ON, Canada) for her advice and support in generating and executing the search.

Conflict of interest: None declared.

Support statement: This study was supported by funding from the Peter Munk Chair in Structural Heart Disease Intervention.

\section{References}

1 van der Linde D, Konings EE, Slager MA, et al. Birth prevalence of congenital heart disease worldwide: a systematic review and meta-analysis. J Am Coll Cardiol 2011; 58: 2241-2247.

2 Marelli AJ, Ionescu-Ittu R, Mackie AS, et al. Lifetime prevalence of congenital heart disease in the general population from 2000 to 2010. Circulation 2014; 130: 749-756.

3 Botto LD, Correa A, Erickson JD. Racial and temporal variations in the prevalence of heart defects. Pediatrics 2001; 107: E32.

4 Torres AJ. Hemodynamic assessment of atrial septal defects. J Thorac Dis 2018; 10: Suppl. 24, S2882-S2889.

5 Fuse S, Tomita H, Hatakeyama K, et al. Effect of size of a secundum atrial septal defect on shunt volume. Am J Cardiol 2001; 88: 1447-1450.

6 Tuder RM, Stacher E, Robinson J, et al. Pathology of pulmonary hypertension. Clin Chest Med 2013; 34: 639-650.

7 Sachweh JS, Daebritz SH, Hermanns B, et al. Hypertensive pulmonary vascular disease in adults with secundum or sinus venosus atrial septal defect. Ann Thorac Surg 2006; 81: 207-213.

8 Stout KK, Daniels CJ, Aboulhosn JA, et al. 2018 AHA/ACC guideline for the management of adults with congenital heart disease: a report of the American College of Cardiology/American Heart Association Task Force on Clinical Practice Guidelines. Circulation 2019; 139: e698-e800.

9 Akagi T, Kijima Y, Takaya Y, et al. Treat and repair strategy in patients with atrial septal defect and significant pulmonary arterial hypertension. Circ J 2016; 80: 227-234.

10 Galie N, Humbert M, Vachiery JL, et al. 2015 ESC/ERS Guidelines for the diagnosis and treatment of pulmonary hypertension: the Joint Task Force for the Diagnosis and Treatment of Pulmonary Hypertension of the European Society of Cardiology (ESC) and the European Respiratory Society (ERS): endorsed by: Association for European Paediatric and Congenital Cardiology (AEPC), International Society for Heart and Lung Transplantation (ISHLT). Eur Heart J 2016; 37: 67-119.

11 Engelfriet P, Meijboom F, Boersma E, et al. Repaired and open atrial septal defects type II in adulthood: an epidemiological study of a large European cohort. Int J Cardiol 2008; 126: 379-385.

12 McLaughlin VV, Presberg KW, Doyle RL, et al. Prognosis of pulmonary arterial hypertension: ACCP evidence-based clinical practice guidelines. Chest 2004; 126: Suppl. 1, 78S-92S.

13 Simonneau G, Montani D, Celermajer DS, et al. Haemodynamic definitions and updated clinical classification of pulmonary hypertension. Eur Respir J 2019; 53: 1801913.

14 Oster $\mathrm{M}$, Bhatt $\mathrm{AB}$, Zaragoza-Macias $\mathrm{E}$, et al. Interventional therapy versus medical therapy for secundum atrial septal defect: a systematic review (part 2) for the 2018 AHA/ACC Guideline for the Management of Adults With Congenital Heart Disease: a report of the American College of Cardiology/American Heart Association Task Force on Clinical Practice Guidelines. I Am Coll Cardiol 2019; 73: 1579-1595.

15 Shah D, Azhar M, Oakley CM, et al. Natural history of secundum atrial septal defect in adults after medical or surgical treatment: a historical prospective study. Br Heart J 1994; 71: 224-227.

16 Schwerzmann M, Pfammatter JP. Approaching atrial septal defects in pulmonary hypertension. Expert Rev Cardiovasc Ther 2015; 13: 693-701.

17 Varma C, Benson LN, Silversides C, et al. Outcomes and alternative techniques for device closure of the large secundum atrial septal defect. Catheter Cardiovasc Interv 2004; 61: 131-139.

18 Gabriels C, De Meester P, Pasquet A, et al. A different view on predictors of pulmonary hypertension in secundum atrial septal defect. Int J Cardiol 2014; 176: 833-840.

19 D'Alto M, Mahadevan VS. Pulmonary arterial hypertension associated with congenital heart disease. Eur Respir Rev 2012; 21: 328-337.

20 King TD, Thompson SL, Steiner C, et al. Secundum atrial septal defect: nonoperative closure during cardiac catheterization. JAMA 1976; 235: 2506-2509.

21 Du Z-D, Hijazi ZM, Kleinman CS, et al. Comparison between transcatheter and surgical closure of secundum atrial septal defect in children and adults: results of a multicenter nonrandomized trial. J Am Coll Cardiol 2002; 39: 1836-1844.

22 Butera G, Biondi-Zoccai G, Sangiorgi G, et al. Percutaneous versus surgical closure of secundum atrial septal defects: a systematic review and meta-analysis of currently available clinical evidence. EuroIntervention 2011; 7: 377-385.

23 Opotowsky AR, Landzberg MJ, Kimmel SE, et al. Trends in the use of percutaneous closure of patent foramen ovale and atrial septal defect in adults, 1998-2004. JAMA 2008; 299: 521-522.

24 Moher D, Shamseer L, Clarke M, et al. Preferred reporting items for systematic review and meta-analysis protocols (PRISMA-P) 2015 statement. Syst Rev 2015; 4: 1.

25 Covidence systematic review software. Veritas Health Innovation, Melbourne, Australia. www.covidence.org

26 Moola S, Munn Z, Tufanaru C, et al. Chapter 7: Systematic reviews of etiology and risk. In: Aromataris E, Munn Z, eds. Joanna Briggs Institute Reviewer's Manual, Adelaide, The Joanna Briggs Institute, 2017.

27 R Core Team. R: A language and environment for statistical computing. Vienna, R Foundation for Statistical Computing, 2019.

28 DerSimonian R, Laird N. Meta-analysis in clinical trials. Control Clin Trials 1986; 7: 177-188.

29 Viechtbauer W. Conducting meta-analyses in R with the metafor package. J Stat Softw 2010; 36: 1-48. 
30 Higgins JP, Thompson SG, Deeks JJ, et al. Measuring inconsistency in meta-analyses. BMJ 2003; 327: 557-560.

31 Veldtman GR, Razack V, Siu S, et al. Right ventricular form and function after percutaneous atrial septal defect device closure. J Am Coll Cardiol 2001; 37: 2108-2113.

32 de Lezo JS, Medina A, Romero M, et al. Effectiveness of percutaneous device occlusion for atrial septal defect in adult patients with pulmonary hypertension. Am Heart J 2002; 144: 877-880.

33 Bruch L, Winkelmann A, Sonntag S, et al. Fenestrated occluders for treatment of ASD in elderly patients with pulmonary hypertension and/or right heart failure. J Interv Cardiol 2008; 21: 44-49.

34 Balint $\mathrm{OH}$, Samman $\mathrm{A}$, Haberer $\mathrm{K}$, et al. Outcomes in patients with pulmonary hypertension undergoing percutaneous atrial septal defect closure. Heart 2008; 94: 1189-1193.

35 Yong G, Khairy P, De Guise P, et al. Pulmonary arterial hypertension in patients with transcatheter closure of secundum atrial septal defects: a longitudinal study. Circ Cardiovasc Interv 2009; 2: 455-462.

36 Yalonetsky S, Lorber A. Comparative changes of pulmonary artery pressure values and tricuspid valve regurgitation following transcatheter atrial septal defect closure in adults and the elderly. Congenit Heart Dis 2009; 4: $17-20$.

37 Altindag T, Roos-Hesselink JW, Cuypers JA, et al. Transcatheter device closure of atrial septal defects in patients aged 40 years and older. Neth Heart J 2010; 18: 537-542.

38 Humenberger M, Rosenhek R, Gabriel H, et al. Benefit of atrial septal defect closure in adults: impact of age. Eur Heart J 2011; 32: 553-560.

39 Huang ZW, Fan ZX, Sun JT, et al. The short- and medium-term results of transcatheter closure of atrial septal defect with severe pulmonary arterial hypertension. Heart Vessels 2012; 27: 603-609.

40 Kefer J, Sluysmans T, Hermans C, et al. Percutaneous transcatheter closure of interatrial septal defect in adults: procedural outcome and long-term results. Catheter Cardiovasc Interv 2012; 79: 322-330.

41 Nakagawa K, Akagi T, Taniguchi M, et al. Transcatheter closure of atrial septal defect in a geriatric population. Catheter Cardiovasc Interv 2012; 80: 84-90.

42 Mangiafico S, Monte IP, Tropea L, et al. Long-term results after percutaneous closure of atrial septal defect: cardiac remodeling and quality of life. J Cardiovasc Echogr 2013; 23: 53-59.

43 Wang JK, Chiu SN, Lin MT, et al. Mid-to-long-term follow-up results of transcatheter closure of atrial septal defect in patients older than 40 years. Heart Vessels 2017; 32: 467-473.

44 Dalvi B, Jain S, Pinto R. Device closure of atrial septal defect with severe pulmonary hypertension in adults: patient selection with early and intermediate term results. Catheter Cardiovasc Interv 2019; 93: 309-315.

45 Zwijnenburg RD, Baggen VJM, Geenen LW, et al. The prevalence of pulmonary arterial hypertension before and after atrial septal defect closure at adult age: a systematic review. Am Heart J 2018; 201: 63-71.

46 Beauchesne LM, Dennie CJ. Imaging in pulmonary hypertension: echocardiography, computed tomography and cardiac magnetic resonance imaging. Can J Cardiol 2010; 26: 17B-20B.

47 Wang B, Feng Y, Jia L, et al. Accuracy of Doppler echocardiography in the assessment of pulmonary arterial hypertension in patients with congenital heart disease. Eur Rev Med Pharmacol Sci 2013; 17: 923-928.

48 Chemla D, Castelain V, Humbert $\mathrm{M}$, et al. New formula for predicting mean pulmonary artery pressure using systolic pulmonary artery pressure. Chest 2004; 126: 1313-1317.

49 Greiner S, Jud A, Aurich M, et al. Reliability of noninvasive assessment of systolic pulmonary artery pressure by Doppler echocardiography compared to right heart catheterization: analysis in a large patient population. $\mathrm{J} \mathrm{Am}$ Heart Assoc 2014; 3: e001103.

50 Hoeper MM, Humbert M. The new haemodynamic definition of pulmonary hypertension: evidence prevails, finally! Eur Respir J 2019; 53: 1900038.

51 Duffels M, van Loon L, Berger R, et al. Pulmonary arterial hypertension associated with a congenital heart defect: advanced medium-term medical treatment stabilizes clinical condition. Congenit Heart Dis 2007; 2: 242-249.

52 Jategaonkar S, Scholtz W, Schmidt $\mathrm{H}$, et al. Cardiac remodeling and effects on exercise capacity after interventional closure of atrial septal defects in different adult age groups. Clin Res Cardiol 2010; 99: 183-191.

53 Woo SB, Jang SI, Kim SH, et al. Transcatheter closure of secundum atrial septal defect in patients over 60 years old. Korean Circ J 2013; 43: 110-114.

54 Swan L, Varma C, Yip J, et al. Transcatheter device closure of atrial septal defects in the elderly: technical considerations and short-term outcomes. Int J Cardiol 2006; 107: 207-210. 